\title{
Effect of Façade Type on the Cooling Load of a Multi-Storey Building
}

\author{
Rafat Al-Waked * \\ College of Engineering, Prince Mohammad Bin Fahd University (PMU), Al Khobar, Kingdom of Saudi Arabia, 31952
}

\begin{abstract}
The thermal and energy implications of a number of façade configurations on the lowest potential energy consumption for a multi-storey building have been investigated using the IES Virtual Environment software package. A preliminary 3-Dimensional computer model of the building was created and a number of different analyses were undertaken to ascertain the optimum façade configuration from an occupant comfort and thermal energy consumption perspective. Results have demonstrated that any one façade or glazing type will not provide the best solution in terms of peak loads, overall energy consumption, occupant comfort and cost. Any solution must therefore be a compromise between these competing factors. On the basis of these results, it has been found that a higher performance glazing results in the lowest peak cooling load, however, a more moderate performance glazing results in the best overall energy consumption.
\end{abstract}

Keywords: Passive Cooling, Thermal Analysis, Energy Performance, Window Glazing.

- $\quad$ Minimizing reflectivity

- Maximizing energy efficiency.

\section{Introduction}

The Vision Development is a 72 storey mixed used commercial, retail and residential tower located in Brisbane, Australia. The building provides 12 levels of commercial office space, three levels of retail space and 56 levels of residential apartments [1].

The façade options study has been undertaken using the IES Virtual Environment software package incorporating the powerful Apache thermal software module [2]. A preliminary 3-Dimensional computer model of a typical floor of the building's commercial area, shown in Figure 1, was undertaken and analyses were carried out to ascertain the optimum façade configuration from an occupant thermal comfort and energy consumption perspective.

\section{Glazing Terminology}

\subsection{Glass Selection}

Glass selection for any building requires consideration of a number of competing factors [3]:

- Maximizing daylight

- Minimizing glare

- Controlling solar gain and seasonal heat gain/ heat loss

- Maintaining visibility

${ }^{*}$ Corresponding author. Tel.: +96638499765

Fax:+96638498890; E-mail: ralwaked@ @mu.edu.sa

(C) 2010 International Association for Sharing Knowledge and Sustainability

DOI: $10.5383 /$ ijtee.01.01.002
Glazing selection is also a matter of personal preference in so much as the architectural intent will often set the extent, color and arrangement of the façade glazing.

\subsection{Solar Radiation}

Solar radiation is broad spectrum electromagnetic energy which comprises both visible and nonvisible radiation components in the wavelength range $0.3-3.0 \mu \mathrm{m}$.

The visible spectrum comprises light in the wavelength ranges of $0.35 \mu \mathrm{m}$ to $0.78 \mu \mathrm{m}$. The nonvisible spectrum comprises ultra-violet (UV) light in the range $0.35 \mu \mathrm{m}$ and infra-red (IR) light in the range greater than $0.78 \mu \mathrm{m}$. The visible spectrum represents approximately $46 \%$ of the sun's energy whilst the UV component represents approximately $9 \%$ and the remaining $45 \%$ is in the IR range.

Short wave radiation is radiation in the range of 0.3 to $3 \mu \mathrm{m}$ and represents all incident solar radiation including visible light. Long wave radiation comprises radiation with wavelengths greater than $3.0 \mu \mathrm{m}$ and originates from radiation sources with surface temperatures close to normal ambient temperatures. Generally, all reflected radiation is long wave radiation.

The composition of radiant energy, whether long wave or short wave affects the performance of glazing and windows both visually as well as from an energy perspective. The amount of 
energy, both heat and light, which is transferred through a glass element, depends on the glass properties. These are three main related properties; Transmission $(\tau)$ reflection $(\rho)$ and absorption $(\alpha)$ as shown in Figure 2. These properties represent the percentage of energy transmitted through the glass, reflected by the glass and absorbed by the glass so that [5]:

$$
\tau+\rho+\alpha=1.0
$$

A fourth property is the emissivity of the glass and this value determines the amount of absorbed energy radiated by the glass. Emissivity, $\varepsilon$, is a value between 0 and 1.0.

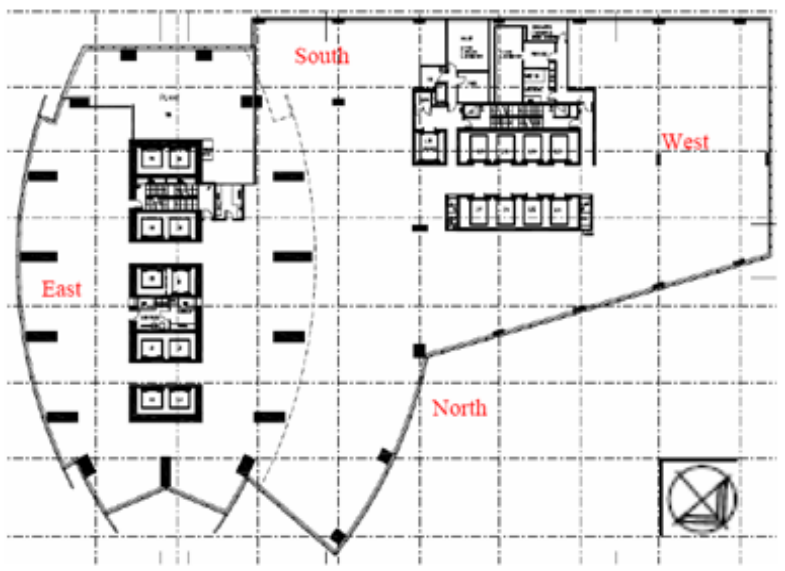

Fig. 1. Typical Floor Plan [4].

Selective surfaces are surfaces that typically have high absorptivity and low emissivity, whilst spectrally selective surfaces have varying properties for different wave lengths of radiation. Low coatings for glass typically have emissivity values of 0.2 whilst clear glass has an emissivity of approximately 0.85 .

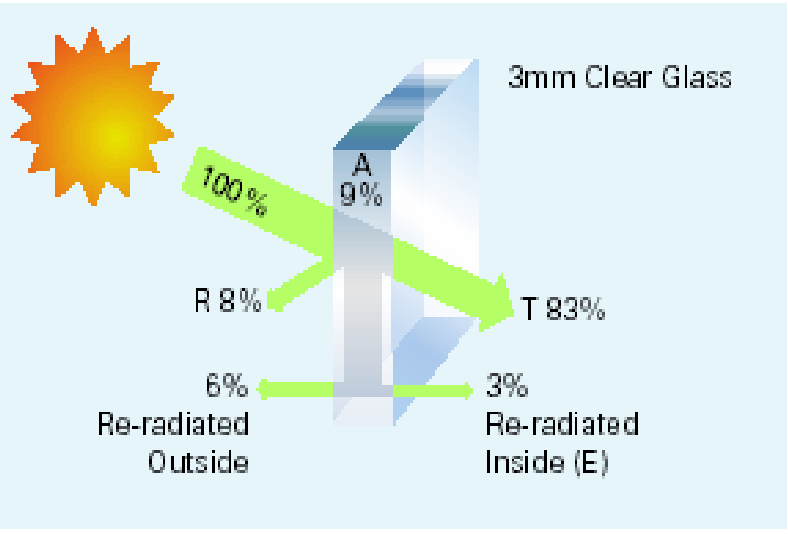

Fig. 2. Effect of glazing properties on incident solar energy [6].

\subsection{Other Heat Transfer Concepts}

Heat transfer through windows and glass occurs through a combination of conduction and radiation. The glass interacts with the external and internal environment through a combination of convection and radiation. Hence it is through a combination of these three mechanisms that heat moves across a glazed window as shown in Figure 3.

A number of parameters measure windows performance with respect to these three mechanisms. These are:

\subsection{1. $U$-Value}

The U-value (measured in $\mathrm{W} / \mathrm{m}^{2} . \mathrm{K}$ ) of a glazing element is the overall heat transfer co-efficient and is a measure of how much heat energy can be lost or gained through the element for a given thickness and temperature difference. The higher the UValue, the greater the heat transfer. $3 \mathrm{~mm}$ clear float glass typically has a U-Value of around $6 \mathrm{~W} / \mathrm{m}^{2} . \mathrm{K}$. Whilst a sealed double glazed window unit will typically have a U-Value of $2.2-3.5 \mathrm{~W} / \mathrm{m}^{2} . \mathrm{K}$. Vacuum glazed or gas-filled double glazed units may have a U-value less than $0.8 \mathrm{~W} / \mathrm{m}^{2} . \mathrm{K}$.

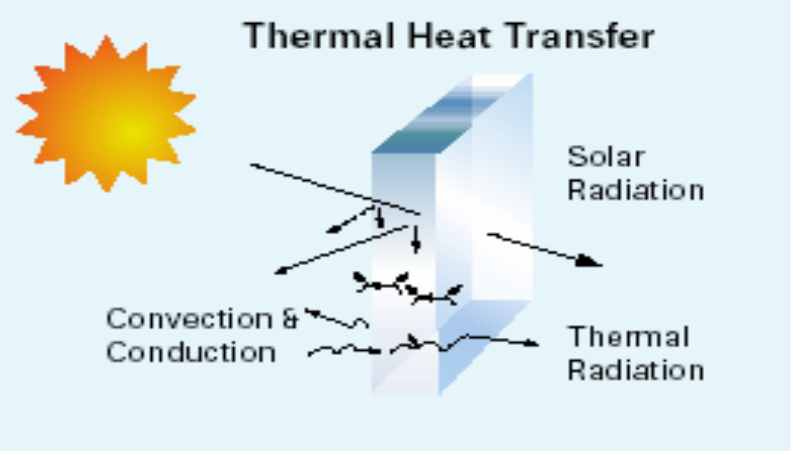

Fig. 3. Mechanisms of heat transfer [6].

\subsubsection{Visible Light Transmission}

Visible light transmission (VLT) is a measure of the amount of energy in the visible spectrum $(0.35-0.78 \mu \mathrm{m})$ transmitted through the glazing. $3 \mathrm{~mm}$ clear float glass has a typical VLT of $86 \%$ with $8 \%$ reflected and the remaining $6 \%$ absorbed by the glass. The amount of light transmitted depends on the thickness and color of the glass as well as the use of laminating, tinting or other special film coatings. For example, a $6.38 \mathrm{~mm}$ laminated grey tint glass will transmit around $44 \%$ visible light, reflect around 5\% of the light energy and absorb the remaining $51 \%$. The absorbed energy causes the glass temperature to increase and this heat is then emitted by the glass as radiant energy.

\subsubsection{Shading Co-efficient}

The shading co-efficient (SC) represents the amount of directly transmitted and absorbed energy transferred to a space through a piece of glass compared to a standard piece of $3 \mathrm{~mm}$ clear float glass at the same conditions. $3 \mathrm{~mm}$ clear float glass therefore has a SC of 1.0 whilst a $6 \mathrm{~mm}$ grey tinted glass has a shading co-efficient of around 0.69 . The lower the SC value, the less solar radiation is transferred through the glass.

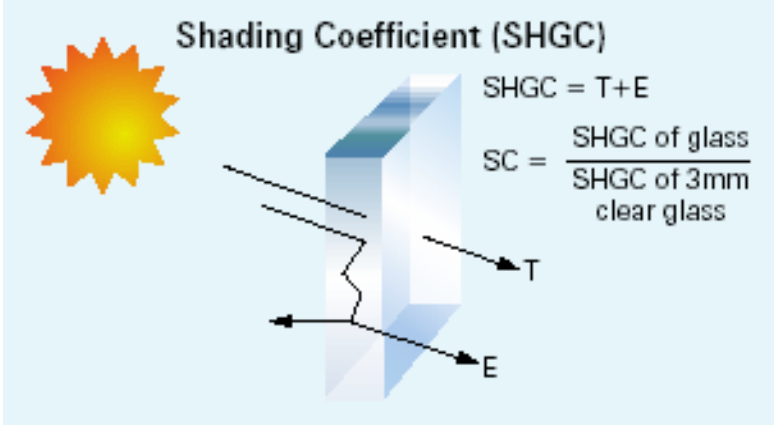

Fig. 4. Mechanisms of heat transfer [6]. 


\subsubsection{Solar Heat Gain Co-Efficient}

The solar heat gain co-efficient (SHGC) is the proportion of directly transmitted and absorbed solar energy transferred through the glazing compared to the incident solar radiation on the glass. The SHGC value depends on the orientation of the glass, the ambient temperature and air speed on each side of the glass as well as spectral properties of the glass. Under ASHRAE standard conditions the SHGC is equal to $0.87 \mathrm{x} \mathrm{SC}$, since under these conditions the $3 \mathrm{~mm}$ clear float glass has a SHGC value of 0.87 .

If the actual external wind speed is lower or the internal air speed is higher than the standard conditions as defined by ASHRAE then the SHGC and therefore the SC will increase. Standard ASHRAE conditions assume still air conditions inside and $12 \mathrm{~km} / \mathrm{hr}$ wind outside.

Assuming the external condition is still air and the internal conditions have air at $24^{\circ} \mathrm{C}$ and $1.5 \mathrm{~m} / \mathrm{s}$ moving past a $6 \mathrm{~mm}$ grey tint glazing then the SHGC value may be closer to 0.81 and the shading co-efficient, SC of 0.89 compared to 0.69 . To reduce air conditioning loads the SHGC should typically be kept below 0.4, however, this will also reduce the amount of visible light transmitted through the façade.

\subsubsection{Luminous Efficacy (VLT/SHGC Ratio)}

The luminous efficacy or coolness factor indicates how thermally efficient the glass is. It is the ratio of VLT/SHGC and is a measure of a glass material's ability to transmit light whilst rejecting heat. Ratios greater than 1.3 are considered to be good and the higher the better. Typically, green and blue/green tints have higher values than grey or bronze tints. In some extreme examples, grey and bronze tints may significantly reduce visible light transmission whilst keeping heat gains high.

\subsection{Color}

Generally, architectural glazings come in four basic colors; grey, bronze/brown, blue and green as well as clear untinted glass. Untinted glass actually has a green / blue tint due to the presence of iron. White glass has low iron content and reduces this tint.

The actual color of the glass has two effects. It reduces the amount of visible light transmitted as well as distorting the colors viewed through the glass. Grey tints give lower levels of color distortion whilst bronze and brown tints give higher levels. Grey and bronze tints are less effective at reducing long wavelength heat transmission, whilst significantly reducing visible light transmission.

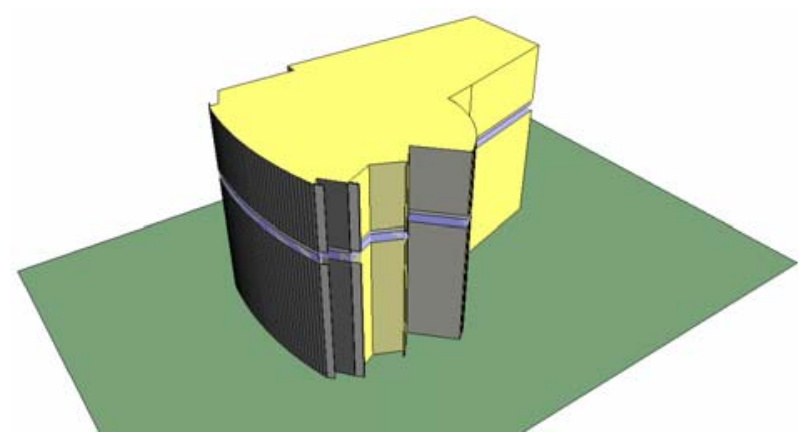

Fig. 5. General view of the modeled building.

\section{Input Data Validation}

The analysis has been undertaken for Brisbane city, Australia. The model maintains an internal air temperature of $22.5^{\circ} \mathrm{C} \pm$ $1.5^{\circ} \mathrm{C}$ year-round between $8 \mathrm{am}$ and $5 \mathrm{pm}$, ground reflectance of 0.2 , haze factor of 0.9 and height above sea level of $42 \mathrm{~m}$.

The model was constructed as per the architectural drawings. External shading is limited to extensions on the eastern façade as shown in the following images and the floor plan. The commercial spaces above and below the typical floor are included for shading and elevation purposes but do not influence the actual analysis of the typical floor.

The typical floor (level 10) modeled has an approximate Net Level Area (NLA) of $4,400 \mathrm{~m}^{2}$. A general view of the model is shown in Figure 5.

The Sun path diagram for Brisbane, as illustrated in Figure 6, has been used in the analysis of solar effects on the facades.

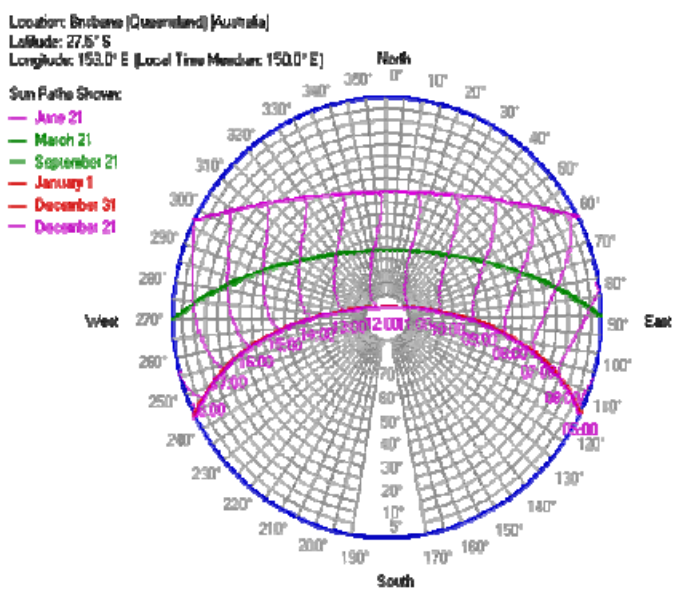

Fig. 6. Brisbane's sun path diagram.

A number of different glazing selections have been recommended for investigation as part of this study. Details of six different $G$ James Glass glazing types are listed in table 1. The design glazing, Glazing 1, represents the original design parameters for the façade. Details of the materials of constructions, fabric analysis and operational parameters are detailed in table 2 according to the following [6]:

- Design Glazing (option A)

- GJames Solarplus LE54 on Grey (option B)

- GJames Solarplus LE40 on Clear (option C)

- GJames Solarplus LE80 on Grey (option D)

- GJames Solarplus LE70 on Green (option E)

- GJames DLE70 on Grey (option F)

- GJames LE54i on Green (option G).

\section{Simulation Results}

A single level was used to enable comparative analysis of the different glazing without the need for detailed and costly simulation of the full building. As such, results provide indicative performance of the different facades relative to each other, but do not necessarily provide complete details of the expected final energy performance.

Seven scenarios were modeled and results were presented in Table 3. The simulation results were analyzed based on the following parameters: 
- Occupant comfort; whereby dry resultant temperature is the parameter of interest. The dry resultant temperature is a function of the mean value of the room air temperature and radiant temperatures. Otherwise known as Comfort Temperature.
- Annual Energy consumption on a per $\mathrm{kWhr} / \mathrm{m}^{2}$ basis [7].

- Resultant peak cooling load experienced in the model's respective perimeter zones in $\mathrm{W} / \mathrm{m}^{2} /$ annum [8].

Table 1. Glazing performance characteristics

\begin{tabular}{|c|c|c|c|c|c|c|c|c|c|c|}
\hline & & & & & Perfo & ance & aracte & fics & & \\
\hline & Product & & $\begin{array}{l}\text { e Prop } \\
(\%)\end{array}$ & & & $\begin{array}{l}\text { Prope } \\
(\%)\end{array}$ & & $\begin{array}{l}\text { Solar } \\
\text { Heat }\end{array}$ & $\begin{array}{l}\text { U- Value } \\
\left(\mathrm{W} / \mathrm{m}^{2} \mathrm{~K}\right)\end{array}$ & $\begin{array}{l}\text { Shading } \\
\text { Coeff. }\end{array}$ \\
\hline & & Trans & $\begin{array}{l}\text { Ext. } \\
\text { Refl. }\end{array}$ & $\begin{array}{c}\text { Int } \\
\text { Refl. }\end{array}$ & $\begin{array}{c}\text { Direct } \\
\text { Trans }\end{array}$ & $\begin{array}{l}\text { Ext } \\
\text { Refl. }\end{array}$ & $\begin{array}{l}\text { Int. } \\
\text { Refl. }\end{array}$ & $\begin{array}{l}\text { Gain } \\
\text { Coeff. }\end{array}$ & & \\
\hline 1 & Design Glazing & - & - & - & - & - & - & - & 1.8 & 0.44 \\
\hline 2 & $\begin{array}{l}\text { Twin Glaze unit } 6 \mathrm{~mm} \text { Solarplus LE5 } 4 \text { on } \\
\text { Grey } 12 \mathrm{~mm} \text { airspace } 6 \mathrm{~mm} \text { clear }\end{array}$ & 23 & 6 & 16 & 15 & 10 & 24 & 0.24 & 1.8 & 0.28 \\
\hline 3 & $\begin{array}{l}\text { Twin Glaze unit } 6 \mathrm{~mm} \text { Solarplus LE } 40 \text { on } \\
\text { Clear } / 12 \mathrm{~mm} \text { Air } / 6 \mathrm{~mm} \text { Clear }\end{array}$ & 36 & 18 & 17 & 22 & 24 & 24 & 0.29 & 1.8 & 0.34 \\
\hline 4 & $\begin{array}{l}\text { Twin Glaze unit } 6 \mathrm{~mm} \text { Solarplus LE70 on } \\
\text { Green } 12 \mathrm{~mm} \text { airspace } 6 \mathrm{~mm} \text { Clear }\end{array}$ & 54 & 10 & 15 & 25 & 10 & 24 & 0.33 & 1.8 & 0.38 \\
\hline 5 & $\begin{array}{l}\text { Twin Glaze unit } 6 \mathrm{~mm} \text { Solarplus LE } 80 \text { on } \\
\text { grey } 12 \mathrm{~mm} \text { airspace } 6 \mathrm{~mm} \text { clear }\end{array}$ & 34 & 7 & 13 & 23 & 10 & 23 & 0.32 & 1.8 & 0.36 \\
\hline 6 & $\begin{array}{l}\text { Twin Glaze unit } 6 \mathrm{~mm} \text { Solarplus DLE70 } \\
\text { on grey } 12 \mathrm{~mm} \text { airspace } 6 \mathrm{~mm} \text { clear }\end{array}$ & 29 & 6 & 11 & 15 & 13 & 31 & 0.23 & 1.7 & 0.27 \\
\hline 7 & $\begin{array}{l}\text { Twin Glaze unit } 6 \mathrm{~mm} \text { Solarplus LE5 } 4 \mathrm{i} \\
\text { on greEN } 12 \mathrm{~mm} \text { airspace } 6 \mathrm{~mm} \text { clear }\end{array}$ & 42 & 8 & 16 & 20 & 9 & 24 & 0.28 & 1.8 & 0.32 \\
\hline
\end{tabular}

Table 2. Façade types analyzed.

\begin{tabular}{lccccccc}
\hline Façade Option & A & B & C & D & E & F & G \\
\hline & Design & LE54 & LE40 & LE80 & LE70 & DLE70 & LE54i \\
Glazing Type & & Grey & Clear & on & on & on & on \\
SC & 0.44 & 0.28 & 0.34 & 0.36 & 0.38 & 0.27 & 0.32 \\
$\mathrm{U}\left(\mathrm{W} / \mathrm{m}^{2} . \mathrm{K}\right)$ & 1.8 & 1.8 & 1.81 & 1.8 & 1.8 & 1.7 & 1.8
\end{tabular}

Table 3. Results of Façade types analyses.

\begin{tabular}{lccccccc}
\hline Façade Option & A & B & C & D & E & F & G \\
\hline $\begin{array}{l}\text { Energy }(\mathbf{k W h r} / \mathbf{a} / \mathbf{m} 2) \\
\text { Cooling }\end{array}$ & 178 & 170.5 & 173.1 & 176.2 & 177.8 & 171.7 & 172.4
\end{tabular}

\begin{tabular}{lccccccc}
\hline Façade Option & A & B & C & D & E & F & G \\
\hline Cooling Load (W/m2) & 117 & 108 & 105 & 126 & 125 & 142 & 142 \\
East Façade & 123 & 119 & 112 & 139 & 133 & 150 & 150 \\
North Façade & 142 & 139 & 127 & 162 & 154 & 166 & 166 \\
West Façade & 131 & 126 & 119 & 144 & 139 & 114 & 120 \\
South Façade & & & & & & & \\
& A & B & C & D & E & F & G \\
\hline Façade Option & & & & & & & \\
\hline Dry Resultant Temperature & 29.0 & 27.5 & 28.3 & 28.3 & 28.8 & 28.5 & 29.0 \\
East Façade & 27.1 & 27.9 & 28.5 & 28.6 & 26.6 & 28.9 & 29.3 \\
North Façade & 30.0 & 28.5 & 29.0 & 29.8 & 30.0 & 29.5 & 30.0 \\
West Façade & 29.3 & 28.0 & 28.5 & 29.3 & 29.3 & 28.0 & 28.3 \\
South Façade & & & & & & &
\end{tabular}




\section{Analysis}

\subsection{Occupant comfort}

Although the internal air temperature will be controlled by means of a mechanical HVAC system, occupant comfort is also influenced by the temperature of surfaces in the vicinity of the occupant. Radiant heat from windows is a major contributor to occupant discomfort in perimeter zones of commercial buildings. It is therefore desirable to limit the fluctuation of the internal surface temperature of external windows. This can be achieved by means of utilizing external shading, high performance glazing or both.

The analysis has considered the impact of façade performance on occupant comfort within the perimeter zones of the buildings typical floor plate. Each zone is limited to approximately $100 \mathrm{~m}^{2}$ and hence the width of the zone is approximately $2.5 \mathrm{~m}$ to $3.5 \mathrm{~m}$. The dry resultant temperature, which is a combination of air temperature and radiant surface temperature, is used as the measure. A higher glass temperature will result in a higher dry resultant temperature for the same measured air temperature.

Figure 7 shows the dependence of the occupant comfort on the window glazing in use and the location with respect to building orientation. For the eastern side of the building, it has been found that Solarplus LE54 on Grey (option B) resulted in the most comfortable conditions. The same conclusion can be drawn for the western and the southern sides. However, the Solarplus LE70 on Green (option E) resulted in the most comfortable conditions for the northern side.

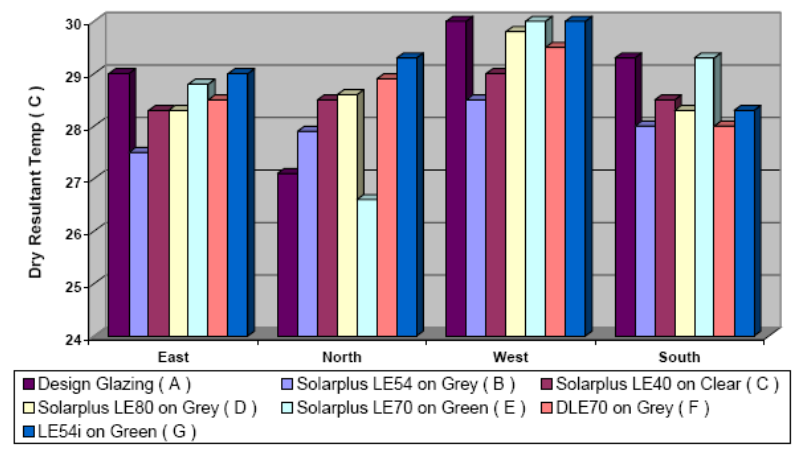

Fig. 7. Dry resultant temperature as a function of window glazing and location.

On the basis of the analysis, option B and option E result in the best overall comfort temperatures. Peak temperatures range from $26.6^{\circ} \mathrm{C}$ to $28.5^{\circ} \mathrm{C}$, whilst the air temperature is maintained between $21^{\circ} \mathrm{C}$ and $24^{\circ} \mathrm{C}$ in the spaces. It may be appropriate to provide different glass types to different facades, however, if a consistent approach is desired, then option B represents the most appropriate choice from a thermal comfort perspective.

\subsection{Annual Energy Consumption}

The annual energy consumption of the different glazing types are presented in Table 3. These values are based on the average value across the whole floor rather than the perimeter zones only. On this basis, option B has been found to be the preferred solution as it yields the lowest annual energy consumption of the five options analyzed.
Option $\mathrm{C}$ has slightly higher overall energy consumption while other options have significantly higher cooling energy requirements. For example increasing the overall energy consumption by $7 \mathrm{kWhr} / \mathrm{m}^{2} /$ annum across a single floor plate of $4,400 \mathrm{~m}^{2}$ increases the annual energy consumption by $30,800 \mathrm{kWhr} /$ annum or $\$ 3,390$ per year at $\$ 0.11$ per $\mathrm{kWhr}$. Across 12 floors of commercial office space this equates to $\$ 40,656$ per year. The commensurate savings in greenhouse gas emissions and therefore improved ability to meet the ABGR [7] star rating requirements are also evident.

The higher performance glazing, whilst reducing peak cooling loads typically increase overall cooling loads as they trap heat in the spaces. Lower performance glazing in warmer climates can obtain free cooling at night time through the façade and the glazing. Lower performance glazing such as option A will result in higher cooling energy requirements as the glass provides limited protection from high solar loads. Higher performance glazing such as option B reduces the impact of the high solar loads whilst still allowing some free cooling at night. In winter time, low performance glazing combined with no facade insulation will result in higher heating loads as the façade will lose considerable heat during night time. Whilst some free heating will be obtained through solar gain during the day, the building has to heat from a lower base temperature resulting in greater heating energy use. In commercial buildings in Queensland with suitable façade treatment and relatively high performance glazing, the need for heating is limited or non-existent. For this building, heating does not represent a significant portion of the energy requirements and the results indicate that cooling is the most important factor to consider.

With regard to the perimeter zones, Figure 8 shows that option $\mathrm{C}$ provides the lowest annual cooling load and is the best performing window glazing across all façades. The difference between option $\mathrm{B}$ and option $\mathrm{C}$ is relatively small. The impact of the façade on the central zones of the building is not negligible, however, and results in option $\mathrm{B}$ representing better overall annual energy consumption compared to option $\mathrm{C}$ despite option $\mathrm{C}$ resulting in lower perimeter loads as demonstrated in the next section.

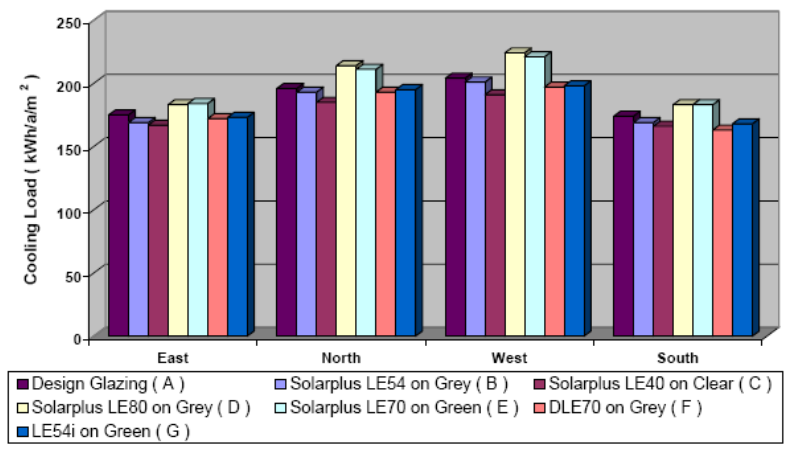

Fig. 8. Annual cooling load as a function of window glazing and Location.

In general, the presence of adjacent buildings provides some benefit to CBD developments by reducing sunlight penetration to lower floors. This shading can also be detrimental increasing the heating requirements of zones. The level of benefit or impact depends on the density, height and orientation of the development and the surrounding structures and will vary between floors. The effect of including the surrounding buildings on the energy consumption has been examined in this study. The results show that including the surrounding 
structure reduces the energy consumption of the building by less than $0.5 \%$ for a typical floor. Given the potential changes to the adjacent buildings during the service life of the development, it is considered appropriate to base the design on an assumption of unobstructed facades and neglect the surrounding structures at this stage of the analysis.

\subsection{Peak Cooling Load}

The peak cooling load demonstrates similar trends as the annual cooling load. By considering the whole of level 10, option B results in the lowest peak cooling load as shown in Figure 9. For all the investigated options, the peak cooling load has varied between $336 \mathrm{~kW}$ and $367 \mathrm{~kW}$. The best performing glazing is the one with the best shading coefficient. When considering the perimeter zones only and presenting the results on per square meter of the floor area basis, option $\mathrm{C}$ becomes the best performing option as shown in Figure 10.

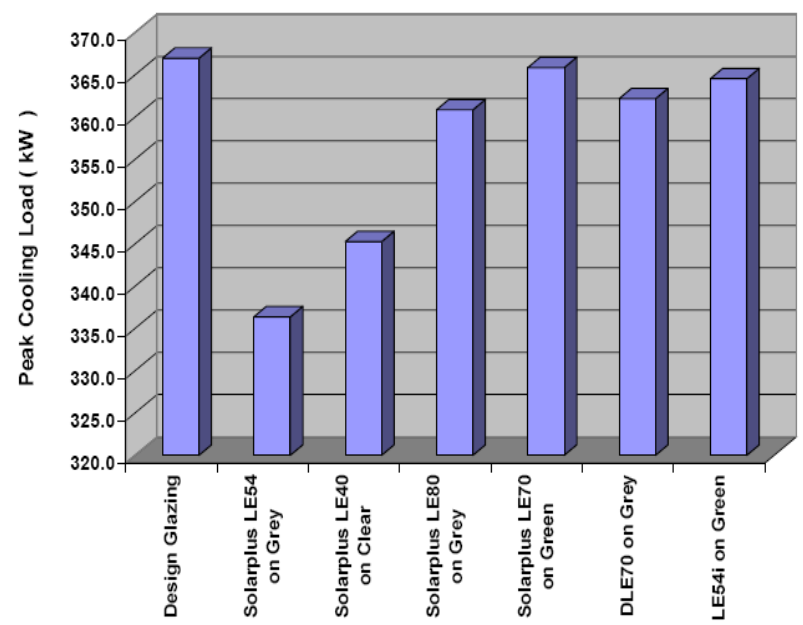

Fig. 9. Peak cooling load as a function of window glazing.

On the basis of peak cooling loads experienced in the respective models' perimeter zones, option $\mathrm{C}$ is the preferred option. The higher performance glass results in lower peak cooling loads, although the overall cooling loads as discussed above are slightly higher for this glazing. Furthermore, it is shown that the western façade has the highest peak load.

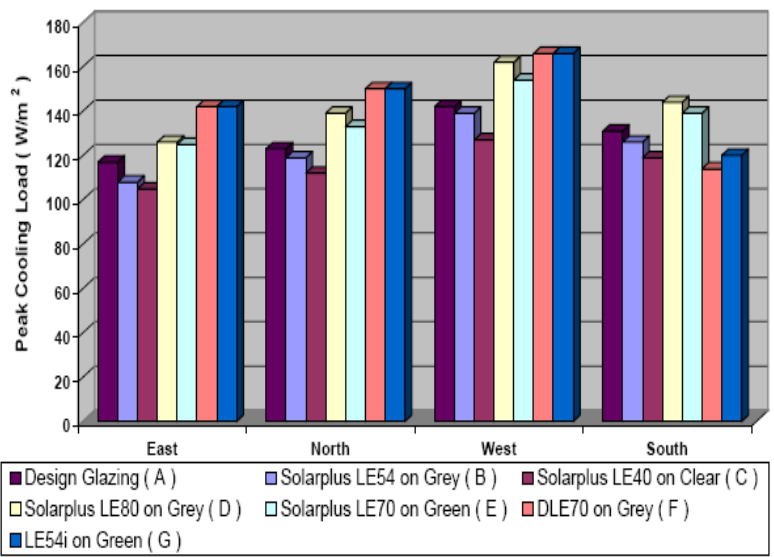

Fig. 9. Peak cooling load as a function of window glazing and location.

\section{Conclusion}

It can be seen that façade performance and hence the overall energy performance of the building is affected by a number of parameters including but not limited to:

- Façade materials and construction

- Glazing selection

- Building Orientation

- External treatment including shading.

Occupant comfort is affected by façade performance and the type of system selected for providing comfort conditions.

Any one façade or glazing type will not provide the best solution in terms of peak loads, overall energy consumption, occupant comfort and cost. Any solution must therefore be a compromise between these competing factors.

This study concludes that a higher performance glazing results in the lowest peak cooling load, however, a more moderate performance glazing results in the best overall energy consumption. Also, it is recommended that Solarplus LE54 on Grey (option B) be selected as the preferred glazing. This analysis does not take into account day lighting factors and the impact of glare on occupant comfort; however, this can be treated separately through the use of internal glare control blinds and appropriately designed external shading. Inclusion of one or both of these parameters will also provide better energy performance, in particular reducing peak cooling loads.

\section{Acknowledgments}

The Author would like to acknowledge the technical comments received from Mr Lester Partridge and Dr Nathan Groenhout of Bassett Consulting Engineers - Australia that enhanced the quality of the presented work.

\section{References}

[1] Groenhout N., "Vision Residential Development-Thermal and Energy Performance Assessment", Bassett Applied Research-Australia, Report number 00280j40a.5rp, 2005

[2] Integrated Environmental Solutions (IES) Ltd, "Thermal Applications Category User Guide- Virtual Environment", Glasgow-UK, 2004, version 5.4

[3] Keiller A., Walker A., Ledbetter S., Wolmuth W., "Guidance on glazing at height", CIRIA, 2005

[4] Al-Waked R., "Vision Commercial Project - Façade Options Report", Bassett Applied Research-Australia, Report number 00280j41b.5rp, 2005

[5] ASHRAE, ASHRAE Handbook: Fundamentals SI Edition, American Society of Heating, Refrigerating and AirConditioning Engineers Inc., 2001

[6] James G., GI James is glass handbook, G. James Australia Pty Ltd, 2000, 1st edition

[7] Australian Building Greenhouse Rating Scheme, ABGR Validation Protocol for Computer Simulations, 2004

[8] Australian Greenhouse Office, Energy Research for the Building Code of Australia, Australian Greenhouse Office, 2000, vol 1 